\title{
How do you define success in stress urinary incontinence treatment?
}

\author{
Philippe E. Zimmern, MD, FACS \\ Professor of Urology, University of Texas Southwestern Medical Center, and Director of the Bladder and Incontinence Treatment Center, Dallas, TX
}

Cite as: Can Urol Assoc J 2012;6(5):S127-8. http://dx.doi.org/10.5489/cuaj.12199

\section{Abstract}

At present, there is no consensus on the best way to define treatment success in the context of stress urinary incontinence (SUI). There is, however, a recognition that it is important to include patient-reported outcomes among the core assessments. Going forward, there is a need to unite outcome reporting tools to be able to compare data across studies and perform meaningful metaanalyses.

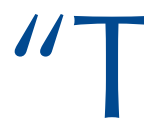

reatment success" in the context of stress urinary incontinence (SUI) can be defined in many different ways. For patients, it may simply be a subjective sense of improved quality of life, recovered comfort, or renewed confidence. For clinical trials, a number of measures have been used to define success, both subjective and objective. These measures have not been consistent from study to study. Likewise, in everyday practice, there is no universally accepted definition of success. This review presents a summary of the different methods we use to define success and discusses their strengths and limitations.

\section{Challenges of the current environment}

The evolution of the field to where we are today has been far from linear. Various specialty societies have recommended the use of different standards for measuring success, and a host of questionnaires have been developed and adopted by different jurisdictions around the world.

Many questionnaires that are helpful for clinical trialists (e.g., the SEAPI QMM ${ }^{1}$ and the Bristol Female Lower Urinary Tract Symptoms Questionnaire ${ }^{2}$ ) are not useful in a practical sense for everyday practitioners. Other, shorter questionnaires are more practical, but there are so many of them and there is no consensus on which should be used. Furthermore, some of these are not easily understood by patients and may be burdensome on staff resources.

A recent review of the literature identified 53 articles published with at least five years of follow-up after SUI treatment. ${ }^{3}$ In these 53 studies, there was considerable variability in the outcomes reported, with an average of two different outcome measures reported in retrospective studies, four in prospective studies, and three in randomized controlled trials (RCTs).

There is also the question of how strict one should be in defining success. The Urinary Incontinence Treatment Network (UITN) sets the bar as high as possible with its definition of "cure." ${ }^{4}$ The UITN criteria insist that a patient be considered strictly "dry" by five parameters: self-reported dryness, no leakage in a three-day voiding diary, negative standardized cough stress test, negative 24-hour pad test and no re-treatment. Applying the UITN model to a clinical trial population shows how strict these criteria are. When they were retrospectively applied to the data from a randomized, controlled trial comparing the tension-free vaginal tape (TVT) procedure and Burch colposuspension, the success rate was less than $10 \% .^{5,6}$

By contrast, if patient satisfaction was used to determine success, the success rate in that same study was approximately $80 \%{ }^{5}$ One might consider those patients who did not meet the UITN criteria, but did report treatment satisfaction as "happy failures."

\section{So what should we use to define success?}

At this stage, there is a consensus that patient-reported outcomes, including impact on quality of life, are very important to assess cure rates after surgical treatment of SUI. This stems, in part, from the observation that there is a discrepancy between patient and physician perception of patient quality of life related to urinary symptoms. ${ }^{7}$ Questionnaires are important tools to capture patientreported outcomes, and research has indicated that they are among the most acceptable assessment tools from a patient perspective (Table 1). ${ }^{8}$

It remains to be determined which particular outcome measures should be used. The Outcome Measure for Incontinence Treatment (OMIT) was designed to study which outcome measures are used by members of the Society of Urodynamics and Female Urology (SUFU). ${ }^{9}$ The results of these surveys showed reasonable consistency for outcome measures used, suggesting that a minimum set of common outcome measures could indeed be developed.

Importantly, among the OMIT survey respondents, there was reasonable consensus that urodynamic testing is not typically necessary for uncomplicated patients. This is supported by the results of the recently reported Value of Urodynamic Evaluation 


\begin{tabular}{lccc}
\hline Table 1. Bothersomeness of study procedures \\
\hline Study procedure & $\begin{array}{c}\text { Moderate/major } \\
\text { bother \% }\end{array}$ & $\begin{array}{c}\text { Most bother } \\
\%\end{array}$ & $\begin{array}{c}\text { Least bother } \\
\%\end{array}$ \\
\hline $\begin{array}{l}\text { Urodynamic } \\
\text { studies }\end{array}$ & 30 & 48 & 2 \\
24-hour pad test & 11 & 9 & 18 \\
Q-tip test & 19 & 11 & 3 \\
$\begin{array}{l}\text { Stress test } \\
\text { 3-day diary }\end{array}$ & 21 & 9 & 2 \\
$\begin{array}{l}\text { Pelvic } \\
\text { examination }\end{array}$ & 10 & 8 & 20 \\
Questionnaires & 10 & 6 & 14 \\
\hline $\begin{array}{l}\text { The first column reports on the collapse of the two categories (moderate and major) for the } \\
\text { bothersomeness of study procedures. The next two columns indicate the patient's response } \\
\text { to the procedure ranked as most or least bothersome. } \\
\text { *Adapted from Zimmern et al. Lessons from a patient experience survey in a randomized } \\
\text { surgical trial of treatment of stress urinary incontinence in women. Int Urogynecol J } \\
\text { 2011;22(10):1273-8. }\end{array}$ \\
\hline
\end{tabular}

(ValUE) trial, which showed that office evaluation alone is not inferior to evaluation with urodynamic testing. ${ }^{10}$

One of the practical problems with collecting outcome data is accessing this information in patient records. Volatile data are often contained in the "free-text" of progress notes, which makes it difficult to extract.

Electronic medical records may offer a solution, if we can configure our data entry to not only fulfil our encounter codes and meet our billing requirements, but also capture a limited set of standard outcome measures retrievable by automated computer programs. ${ }^{11}$

\section{Conclusions}

There is an urgent need to unite outcome-reporting tools to be able to compare studies and perform meaningful meta-analyses. It seems that patient-reported outcomes are the most relevant and should be included among these reporting tools. In terms of record-keeping, clinicians should implement automated systems and retrieval tools that allow for easy data access and the ability to analyze large data sets over time and provide updated information.
Competing interests: Dr. Zimmern has received support from the National Institutes of Health, Urinary Incontinence Treatment Network, The Cain Foundation for Endowment of ABU-ABOG Fellowship, and Astellas.

\section{References}

1. Raz S, Erickson DR. SEAPI QMM incontinence classification system. Neurourol Urodyn 1992;11 (3):18799. http://dx.doi.org/10.1002/nau.1930110302

2. Jackson S, Donovan J, Brookes S, et al. The Bristol Female Lower Urinary Tract Symptoms questionnaire: development and psychometric testing. Br J Urol 1996;77(6):805-12. http://dx.doi.org/10.1046/ j.1464-410X.1996.00186.x

3. Ou R, Zhao H, Xie X-J, et al. Which outcome measure(s) to select for the reporting of a long-term study on the surgical treatment of stress urinary incontinence (SUI) in women. Neurourol Urodyn 2012;31 (2):213.

4. Albo ME, Richter $H E$, Brubaker $L$, et al. Burch colposuspension versus fascial sling to reduce urinary stress incontinence. N Engl J Med 2007;356(21):2143-55. http://dx.doi.org/10.1056/NEJMoa070416

5. Ward K, Hilton P. Prospective multicentre randomised trial of tension-free vaginal tape and colposuspension as primary treatment for stress incontinence. BMJ 2002;325(7355):67. http://dx.doi.org/10.1136/ bmi.325.7355.67

6. Hilton P. Trials of surgery for stress incontinence-thoughts on the 'Humpty Dumpty principle'. Br J Obstet Gynecol 2002;109(10):1081-8. http://dx.doi.org/10.1111/j.1471-0528.2002.02011.x

7. Rodríguez LV, Blander DS, Dorey F, et al. Discrepancy in patient and physician perception of patient's quality of life related to urinary symptoms. Urology 2003;62(1):49-53. http://dx.doi.org/10.1016/ S0090-4295(03)00144-4

8. Zimmern PE, Dandreo KJ, Sirls L, et al. Lessons from a patient experience survey in a randomized surgical trial of treatment of stress urinary incontinence in women. Int Urogynecol J 2011;22(10):1273-8. hittp:// dx.doi.org/10.1007/s00192-011-1507-z

9. Zimmern P, Kobashi K, Lemack G. Outcome measure for stress urinary incontinence treatment (OMIT): results of two society of urodynamics and female urology (SUFU) surveys. Neurourol Urodyn 2010;29(5):715-8. http://dx.doi.org/10.1002/nau.20840

10. Nager CW, Brubaker L, Litman HJ, et al. A randomized trial of urodynamic testing before stress-incontinence surgery. N Engl J Med 2012;366(21):1987-97. http://dx.doi.org/10.1056/NEJMoal 113595

11. Steid M, Zimmern PE. Data for "Free": can an electronic medical record provide outcome data after incontinence/prolapse repair procedures? AUA 2012 Annual Meeting, May 19-23, 2012 (Podium presentation POD02)

Correspondence: Dr. Philippe E. Zimmern, UT Southwestern Medical Center, 5323 Harry Hines Blvd, Dallas, TX 75390; fax: 214-648-8786; philippe.zimmern@utsouthwestern.edu 